\title{
Disorders of Cardiac Repolarization _ Long QT and Short QT Syndromes
}

\author{
Minoru Horie, MD, PhD; Hideki Itoh, MD, PhD
}

\begin{abstract}
The long and short QT syndromes are heterogeneous diseases characterized by abnormal ventricular repolarization and episodes of syncope and/or life-threatening cardiac arrhythmias. Several disease-causing genes have been identified, including those encoding cardiac ion channel-composing proteins. The clinical determination of genotype offers a striking benefit: diagnosis, prediction of clinical phenotype, risk stratification, clinical and genetic counseling, and introduction of therapy. Genetic testing is of special importance for the genotyped patient's family members to prevent unexpected cardiac death. By means of recently advanced methodology in molecular genetics and electrophysiology it is expected that novel genes responsible for these disease entities will be identified. (Circ J 2007; Suppl A: A-50-A-53)
\end{abstract}

Key Words: Long QT syndrome; Short QT syndrome

$\mathbf{T}$ he long QT syndrome (LQTS) is a primary electrical disease characterized by an abnormality in myocardial repolarization that leads to the prolongation of QT interval, morphological changes in T waves and torsades de pointes type of ventricular tachycardia on the surface ECG (Fig 1)!,2 The association between prolongation of the QT interval and cardiac sudden death was implicated soon after the introduction of ECG recording in the clinical setting? In contrast, the short QT syndrome (SQTS) has been ignored for a long time and the first report relating short QT interval with an increased risk for ventricular fibrillation and cardiac sudden death appeared in 20004

In the late 1990s, the advent of the molecular genetic era provided new insights into the mechanisms underlying LQTS, showing that mutations in genes encoding ion channels or their accessory proteins and other membrane proteins cause the disease. These genetic variants alter the function of ion channels governing the repolarization process of the ventricle. To date, 10 distinct genes responsible for LQTS have been identified, including those for Andersen (LQT7) and Timothy (LQT8) syndromes on chromosomes 11q15.5 (KCNQ1; LQT1), 7q35-36 (KCNH2; LQT2), 3p21 (SCN5A; LQT3), 4q25-27 (ANKB; LQT4), 21q22 (KCNE1; LQT5), 21q22 (KCNE2; LQT6), 17q23 (KCNJ2; LQT7), 12p13.3 (CACN1c; LQT8), 3p25 (CAV3; LQT9) and 11q23.3 $(S C N 4 B \text {; LQT10) })^{5-13}$ (Table 1).

In 2004, Brugada et al ${ }^{14}$ reported the first mutation associated with SQTS. It was a KCNH2 mutation, N588K, involving a substitution of lysine for asparagine in position 588 of $\mathrm{KCNH} 2$. Since then 3 disease-causing genes for SQTS have been identified, including genes encoding cardiac ion channel-composing proteins on chromosomes 7q35-36 (KCNH2; SQT1), ${ }^{14}$ 11q15.5 (KCNQ1; SQT2), ${ }^{15,16}$ and $17 \mathrm{q} 23$ (KCNJ2; SQT3) ${ }^{17}$ (Table 2).

(Received February 14, 2007; accepted February 23, 2007) Department of Cardiovascular and Respiratory Medicine, Shiga University of Medical Science, Otsu, Japan

Mailing address: Minoru Horie, MD, Department of Cardiovascular and Respiratory Medicine, Shiga University of Medical Science, Seta Tsukinowa-cho, Otsu 520-2192, Japan. E-mail: horie@belle. shiga-med.ac.jp

\section{LQTS}

The estimated prevalence of LQTS in the general population is 1 in 5,000!8 During an ECG checkup of Japanese school pupils, its prevalence was 1 in $1,200 !^{9}$ The disease is usually inherited as an autosomal dominant trait with incomplete penetrance and variable expression ${ }^{20}$ LQTS has played a key role as a "Rosetta Stone" in the understanding of the general mechanism of ion channel disease. Fig 2 is a schematic explanation of how a functional alteration in ion channels causes prolongation or abbreviation of the QT intervals on ECG. Electrophysiological assays using a heterologous expression system have shown that some mutations in the aforementioned genes induce a gain or loss-of-function in a respective ion channel and thereby modulate the repolarization process. For example, a reduction in outward $\mathrm{K}$ channel currents or an increase in the inward $\mathrm{Na}^{+}$or $\mathrm{Ca}^{2+}$ channel currents would delay repolarization of the action potential, and therefore prolong the QT interval on the surface ECG.

Now that we know most of the genes responsible for repolarization disorder and the resultant clinical phenotypes, molecular testing for mutation screening of disease genes has become feasible. The availability of genetic testing offers the possibility of identifying genetically affected individuals who are, in other words, potential victims of cardiac sudden death. The clinical determination of genotype offers a striking benefit, including diagnosis (family screening and preclinical diagnosis), prediction of clinical phenotype (penetrance, gene-specific clinical manifestations $^{21}$ ), risk stratification (assessment of malignant vs benign mutations ${ }^{22}$ ), clinical and genetic counseling (restriction of physical activity, family planning etc), and therapy (prevention of sudden death by implantable defibrillator (ICD)).

One of the most important aims of genetic testing is to achieve a preclinical diagnosis of LQTS, particularly in family members with incomplete disease expression ${ }^{20}$ or in patients with a forme fruste phenotype?23,24 Molecular genetic examination does strengthen the clinically overt or suspicious diagnosis. However, the genetic variant identified in 
A

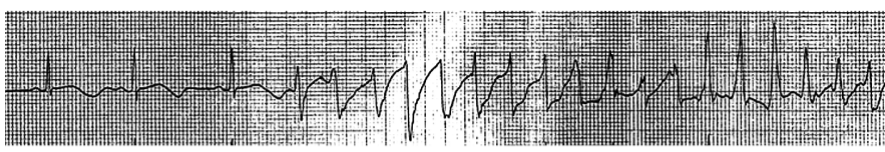

B

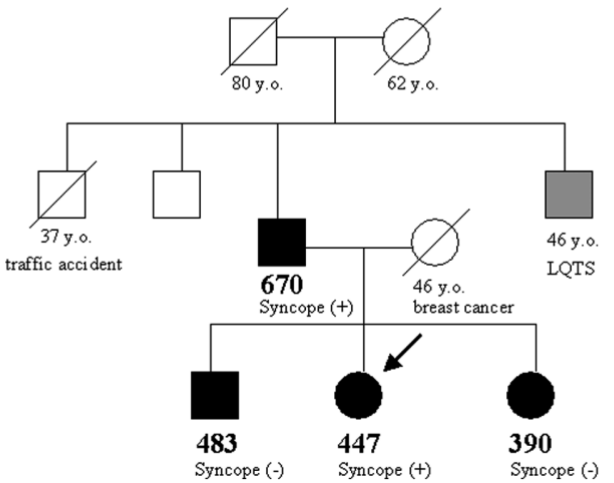

Fig 1. Distinctive ECG features and family tree associated with long QT syndrome (LQTS). (A) Torsades de pointes type of ventricular tachycardia in a patient with genotyped LQT2. Torsade de pointes frequently appeared during sleep. (B) Family analysis associated with the patient. The proband (arrow) was diagnosed as LQT2 with the G572S mutation, which is located in the S5-pore site for the $\mathrm{KCNH} 2$ channel. Heterozygous mutation carriers are indicated by filled symbols, and the numbers below the symbols are the QTc interval at rest. Although the index patient and her father, both carrying the G572S mutation, had syncope at rest, the other 2 mutation carriers remained asymptomatic. The proband had 2 uncles, 1 of whom (open symbol) was genetically negative, and the other (halftone filled) was clinically LQTS, although the genetic data were not available.

Table 1 Gentic Classfication of LQTS

\begin{tabular}{lllc}
\hline \hline Subtypes & Genetic locus & Genes & Ion channel \\
\hline Congenital LQTS (Romano-Ward syndrome) & & & \\
LQT1 & $11(11 p 15.5)$ & KCNQ1 & $I_{K s}$ \\
LQT2 & $7(7 q 35-36)$ & $K C N H 2$ & $I_{K r}$ \\
LQT3 & $3(3 p 21-24)$ & SCN5A & $I_{N a}$ \\
LQT4 & $4(4 q 25-27)$ & Ankyrin-B & {$\left[\mathrm{Ca}^{2+}\right] i$} \\
LQT5 & $21(21 q 22.1-q 22.2)$ & $K C N E 1$ & $I_{K s}$ \\
LQT6 & $21(21 q 22.1-q 22.2)$ & KCNE2 & $I_{K r}$ \\
LQT7 & $17(17 q 23)$ & KCNJ2 & $I_{K l}$ \\
LQT8 & $12 p 13.3$ & $C A C N A 1 C$ & $I_{C a-L}$ \\
LQT9 & $3(3 p 25)$ & $C A V 3$ & $I_{N a}$ \\
LQT10 & $11 q 23.3$ & SCN4B & $I_{N a}$ \\
Congenital LQTS (Jervell and Lange-Nielsen syndrome) & & & \\
JLN1 & $11(11 p 15.5)$ & KCNQ1 (homozygous) & $I_{K s}$ \\
JLN2 & $21(21 q 22.1-q 22.2)$ & KCNE1 (homozygous) & $I_{K s}$
\end{tabular}

LQTS, long QT syndrome.

Table 2 Gentic Classfication of SQTS

\begin{tabular}{|c|c|c|c|c|c|}
\hline Subtype & Gene & Mutations & $Q T c$ & Functions & Reference \\
\hline$S Q T 1$ & $\mathrm{KCNH} 2$ & N588K & 286 & Impaired inactivation of $I_{K r}$ & 14 \\
\hline$S Q T 2$ & $K C N Q 1$ & $V 141 M$ & $A F$ & $\begin{array}{l}\text { Accelerated activation of IKs } \\
\text { Hyperpolarized shift of the activation curve }\end{array}$ & 15 \\
\hline & & V307L & 302 & Faster activation & 16 \\
\hline SQT3 & KCNJ2 & $D 172 N$ & 315 & Larger IKI currents & 17 \\
\hline SQT4 & $C A C N B 2 b$ & $S 481 L$ & $330-370$ & $\begin{array}{l}\text { loss-of-function in L-type Ca channel } \\
\text { Brugada phenotype }\end{array}$ & 39 \\
\hline SQT5 & CACNA1C & $\begin{array}{l}A 39 V \\
G 490 R\end{array}$ & $346-360$ & $\begin{array}{l}\text { loss-of-function in L-type Ca channel } \\
\text { Brugada phenotype }\end{array}$ & 39 \\
\hline
\end{tabular}

SQTS, short QT syndrome; $A F$, atrial fibrillation.

an individual does not directly explain the clinical phenotypes. Mutation carriers may have either no disease phenotype (incomplete penetrance) or present with various degree of clinical manifestations, ranging from asymptomatic with relatively prolonged QT interval and no arrhythmias to those experiencing cardiac arrest even under $\beta$ blocker therapy or after ICD implantation. Thus, inheriting a mutation does not always mean that the individual will present a clinical manifestation of LQTS, but apparently "healthy" mutation carriers have inherited the risk for developing the clinical phenotype. Because congenital LQTS affects the young, all efforts should be made to genotype them for appropriate management of both the patient and the family members who may be at highest risk of sudden death. These efforts are justified by timely therapy with $\beta$ blockers and/or ICD in association with careful clinical follow-up to avoid hypokalemia, bradycardia and drugs that prolong the QT interval, ${ }^{25-27}$ and family education, including the use of an automated electrical defibrillator at home.

Through the elucidation of pathophysiological mechanisms underlying the congenital LQTS during the past decade, we have witnessed the most rapid and fruitful progress in powerful scientific tools: molecular genetics and cellular physiology. We are expecting to identify novel additional genes responsible for the disease. 


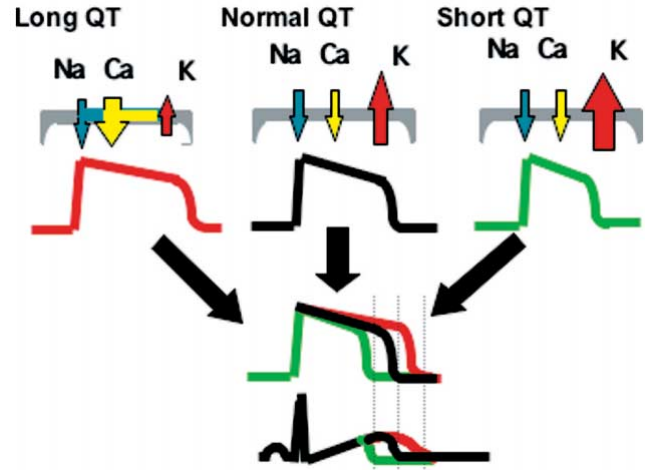

Fig 2. Schematic presentation of ion currents governing the action potential duration in the ventricle. Action potential duration (APD) varies depending on the subtle balance between inward and outward currents. An increase in the inward $\mathrm{Na}^{+}$and $\mathrm{Ca}^{2+}$ currents (blue and yellow arrows) or a decrease in the outward $\mathrm{K}^{+}$current (red arrow) prolongs the APD and causing long QT syndrome (Left panel). Conversely, an increase in the outward $\mathrm{K}^{+}$currents shortens the APD, causing short QT syndrome (Right panel).

\section{SQTS}

SQTS constitutes a new primary electrical abnormality associated with sudden cardiac death.,28 The family first reported by Gussak et $\mathrm{al}^{4}$ consisted of patients with a constantly-shortened QT interval and paroxysmal atrial fibrillation, and one member had died of sudden cardiac death 28 Subsequently, the short QT interval was shown to be associated with sudden cardiac death without structural heart disease ${ }^{14-17}$ The syndrome is now considered as a new cardiac ion channel disease ${ }^{11,28-32}$

The diagnostic criteria for SQTS currently include (1) QTc interval $<330 \mathrm{~ms}$, (2) ventricular tachycardia without structural heart disease, and (3) a family history of sudden cardiac death $3^{33}$ Atrial fibrillation is a characteristic complication, $4,15,33$ and Giustetto et al $^{34}$ demonstrated that $31 \%$ of patients with this syndrome had documented atrial fibrillation, even in young subjects. His group also reported that SQTS could be related to death in early infancy. ${ }^{34}$ Alhough arrhythmogenic triggers in SQTS are incompletely understood, bradycardia may predispose to ventricular tachycardia because the shortened QT interval would become obvious at a lower heart rate $3^{3}$ The induction rate of ventricular tachycardia during electrophysiological examination is apparently very high in SQTS patients, ${ }^{33}$ but the issue remains unclear because information is still limited.

Three responsible genes have been reported to date (Table 2), indicating that SQTS has a genetically heterogeneous background. Brugada et $\mathrm{al}^{14}$ identified the first missense mutation in $\mathrm{KCNH} 2, \mathrm{~N} 588 \mathrm{~K}$, which causes a substitution of lysine for asparagines in position 588 located in the S5-pore loop (SQTS type 1, SQT1). KCNH2 is known as the gene responsible for LQT2, but in contrast to the case in LQTS, N588K in SQTS was found to cause a remarkable gain-of-function in $\mathrm{IKr}$.

The second mutation in SQTS was found in KCNQ1, which encodes the slow component of the delayed rectifier potassium channel (IKs) (SQTS type 2, SQT2)! ${ }^{16} \mathrm{KCNQ1}$ is also a gene responsible for LQTS (LQT1). A missense mutation (V307L) was identified in an index patient with short QT interval and ventricular fibrillation, and it causes a substitution of leucine for valine in position 307 of the
$K C N Q 1$ pore site. Another missense $K C N Q 1$ mutation (V141M) was found in a baby with both shortened QT interval and atrial fibrillation! 15

The latest mutation in SQTS was identified in $K C N J 2$ (type 3, SQT3) ${ }^{17}$ Again, KCNJ2 is responsible for Andersen syndrome (LQT7), encoding the inward rectifier K channel (IK1). The missense KCNJ2 mutation (D172N), causing a substitution of aspartic acid for asparagine in position 172, was shown to induce a gain-of-function of $I_{\mathrm{K}}$. Surface ECG features differ among the 3 subtypes of SQTS. In fact, the $\mathrm{T}$ wave in SQT3 associated with the KCNJ2 mutation is asymmetrical, with a remarkably rapid terminal phase $!^{7}$

All genetic mutations in SQTS cause a gain of the outward $\mathrm{K}$ currents governing the ventricular repolarization, and therefore shortening the QT interval (Table 2). However, the mechanism of inducing the "gain-of-function" differs: (1) impaired inactivation in SQT114,35 (2) accelerated activation and hyperpolazized shift of the activation curve $\mathrm{e}^{15}$ or faster activation ${ }^{16}$ in SQT2, and (3) larger outward currents and depolarized shift of the peak current in SQT3!7

Regarding the arrhythmogeneity in SQTS, Antzelevitch et al have presented the first experimental evidence for the role of transmural dispersion of repolarization (TDR) ${ }^{36}$ They used a pharmacological method with pinacidil, a strong activator of the cardiac ATP-sensitive K channel (IKATP), to mimic a "gain-of-function" in outward K currents in a canine arterially-perfused wedge preparation. Pinacidil caused a heterogeneous abbreviation of the action potential duration in 3 principal cell types spanning the ventricular wall, indicating that TDR could lead to an increased vulnerability to polymorphic ventricular tachycardia.

ICD implantation is the first-line therapy for SQTS patients: ${ }^{37}$ Quinidine can prolong the QT interval and protect against ventricular fibrillation in SQT1 by suppressing $\mathrm{IKr}$, whereas class Ic and III antiarrhythmic drugs (eg, flecainide, sotalol, and ibutilide) are ineffective against ventricular fibrillation? 38

Clinical information on SQTS remains scarce because the patients are very rare compared with those with LQTS. However, there is no doubt that SQTS is strongly associated with an abnormality of the genes encoding cardiac ion channels. Strategies used in the study of LQTS would therefore be useful for further clarification of SQTS.

Note:

After submitting the manuscript, a report on novel mutations causative of SQTS appeared regarding cardiac L-type Ca channel genes: $C A C N B 2 b$ and $C A C N A 1 C$ encoding $\alpha 1$ and $\beta_{2 b}$ subunits of $\mathrm{Ca}_{\text {channel }}{ }^{39}$ (SQT 4 and 5 in Table 2). Functional analyses revealed that 2 mutations of $C A C N A 1 C$ (A39V and G490R) and one CACNB2b (S481L) caused a loss-of-function in $\mathrm{Ca}$ channel currents. The probands' phenotypes carrying these mutations of $\mathrm{Ca}$ channel genes were characterized by cardiac sudden death, atrial fibrillation and Brugada type ECG patterns.

\section{References}

1. Schwartz PJ, Periti M, Malliani A. The long QT syndrome. Am Heart J 1975; 89: 378-390.

2. Moss AJ, Schwartz PJ, Crampton RS, Tzivoni D, Locati EH, MacCluer J, et al. The long-QT syndrome: Prospective longitudinal study of 328 families. Circulation 1991; 84: 1136-1144.

3. Dessertenne F, Fabiato A, Coumel P. Un chapitre nouveau d'electrocardiographie: Les variations progressive de l'amplitude de l'electrocardiogramme. Actual Cardiol Angiol Int 1966; 15: 241-258.

4. Gussak I, Brugada P, Brugada J, Wright RS, Kopecky SL, Chaitman 
BR, et al. Idiopathic short QT interval: A new clinical syndrome? Cardiology 2000; 94: 99-102.

5. Keating M, Atkinson D, Dunn C, Timothy K, Vincent GM, Leppert M. Linkage of a cardiac arrhythmia, the long QT syndrome, and the Harvey ras-1 gene. Science 1991; 252: 704-706.

6. Jiang C, Atkinson D, Towbin JA, Splawski I, Lehmann MH, Li H, et al. Two long QT syndrome loci map to chromosome 3 and 7 with evidence for further heterogeneity. Nat Genet 1994; 8: 141-147.

7. Schott J, Charpentier F, Peltier S, Foley P, Drouin E, Bouhour JB, et al. Mapping of a gene for long QT syndrome to chromosome 4q2527. Am J Hum Genet 1995; 57: 1114-1122.

8. Splawski I, Tristani-Firouzi M, Lehmann MH, Sanguinetti MC, Keating MT. Mutations in the hminK gene cause long QT syndrome and suppress Iks function. Nat Genet 1997; 17: 338-340.

9. Abbott GW, Sesti F, Splawski I, Splawski I, Buck ME, Lehmann $\mathrm{MH}$, et al. MiRP1 forms IKr potassium channels with $H E R G$ and is associated with cardiac arrhythmia. Cell 1999; 97: 175-187.

10. Keating MT, Sanguinetti MC. Molecular and cellular mechanisms of cardiac arrhythmias. Cell 2001; 104: 569-580.

11. Plaster NM, Tawil R, Tristani-Firouzi M, Canun S, Bendahhou S, Tsunoda A, et al. Mutations in Kir2.1 cause the developmental and episodic electrical phenotypes of Andersen's syndrome. Cell 2001; 105: $511-519$.

12. Splawski I, Timothy KW, Sharpe LM, Decher N, Kumar P, Bloise R, et al. $\mathrm{Ca}(\mathrm{V}) 1.2$ calcium channel dysfunction causes a multisystem disorder including arrhythmia and autism. Cell 2004; 119: 19-31.

13. Vatta M, Ackerman MJ, Ye B, Makielski JC, Ughanze EE, Taylor EW, et al. Mutant caveolin-3 induces persistent late sodium current and is associated with long-QT syndrome. Circulation 2006; 114: 2104-2012.

14. Brugada R, Hong K, Dumaine R, Cordeiro J, Gaita F, Borggrefe M, et al. Sudden death associated with short-QT syndrome linked to mutations in HERG. Circulation 2004; 109: 30-35.

15. Hong K, Piper DR, Diaz-Valdecantos A, Brugada J, Oliva A, Burashnikov E, et al. De novo KCNQ1 mutation responsible for atrial fibrillation and short QT syndrome in utero. Cardiovasc Res 2005; 68: 433-440.

16. Bellocq C, van Ginneken AC, Bezzina CR, Alders M, Escande D, Mannens MM, et al. Mutation in the $K C N Q 1$ gene leading to the short QT-interval syndrome. Circulation 2004; 109: 2394-2397.

17. Priori SG, Pandit SV, Rivolta I, Berenfeld O, Ronchetti E, Dhamoon A, et al. A novel form of short QT syndrome (SQT3) is caused by a mutation in the KCNJ2 gene. Circ Res 2005; 96: 800-807.

18. Vincent GM. Long QT syndrome. Cardiol Clin 2000; 18: 309-325.

19. Fukushige T, Yoshinaga M, Shimago A, Nishi J, Kono Y, Nomura $\mathrm{Y}$, et al. Effect of age and overweight on the QT interval and the prevalence of long QT syndrome in children. Am J Cardiol 2002; 89: 395-398

20. Priori SG, Napolitano C, Schwartz PJ. Low penetrance in the longQT syndrome: Clinical impact. Circulation 1999; 99: 529-533.

21. Takenaka K, Ai T, Shimizu W, Kobori A, Ninomiya T, Otani H, et al. Exercise stress test amplifies genotype-phenotype correlation in the LQT1 and LQT2 forms of the long-QT syndrome. Circulation 2003; 106: $838-844$

22. Horie M, Shimizu W, Ohno S, Takenaka K, Yamaguchi M, Shimizu $\mathrm{M}$, et al. Mutation site-specific differences in arrhythmic risk and sensitivity to sympathetic stimulation in the LQT1 form of congenital long QT syndrome: Multicenter study in Japan. J Am Coll Cardiol
2004; 44: 117-125.

23. Kubota T, Shimizu W, Kamakura S, Horie M. Hypokalemia-induced long QT syndrome with an underlying novel missense mutation in S4-S5 linkier of KCNQ1. J Cardiovasc Electrophysiol 2000; 11: $1048-1054$

24. Yoshida H, Horie M, Otani H, Kawashima T, Onishi Y, Sasayama S. Bradycardia-induced long QT syndrome caused by a de novo missense mutation in the S2-S3 inner loop of HERG. Am J Med Genet 2001; 98: $348-352$.

25. Horie M, Makita N, Nakamura T, Ai T, Sasaki K, Yokoi H, et al. Drug-induced long-QT syndrome associated with a subclinical SCN5A mutation. Circulation 2002; 106: 1296-1274.

26. Yang P, Kanki H, Drolet B, Yang T, Wei J, Viswanathan PC, et al. Allelic variants in long-WT disease genes in patients with drug-associated torsades de pointes. Circulation 2002; 105: 1943-1948.

27. Sesti F, Abbott GW, Wei J, Murray KT, Saksena S, Schwartz PJ, et al. A common polymorphism associated with antibiotonic cardiac arrhythmia. Proc Natl Acad Sci USA 2000; 97: 10613-10618.

28. Gaita F, Giustetto C, Bianchi F, Wolpert C, Schimpf R, Riccardi R, et al. Short QT syndrome: A familial cause of sudden death. Circulation 2003; 108: 965-970.

29. Curran ME, Splawski I, Timothy KW, Vincent GM, Green ED, Keating MT. A molecular basis for cardiac arrhythmia: HERG mutations cause long QT syndrome. Cell 1995; 80: 795-803.

30. Wang Q, Shen J, Splawski I, Atkinson D, Li Z, Robinson JL, et al. SCN5A mutations associated with an inherited cardiac arrhythmia, long QT syndrome. Cell 1995; 80: 805-811.

31. Chen Q, Kirsch GE, Zhang D, Brugada R, Brugada J, Brugada P, et al. Genetic basis and molecular mechanism for idiopathic ventricular fibrillation. Nature 1998; 198: 293-296.

32. Chen YH, Xu SJ, Bendahhou S, Wang XL, Wang Y, Xu WY, et al. $K C N Q 1$ gain-of-function mutation in familial atrial fibrillation. Science 2003; 299: 251-254.

33. Schimpf R, Wolpert C, Gaita F, Giustetto C, Borggrefe M. Short QT syndrome. Cardiovasc Res 2005; 67: 357-366.

34. Giustetto C, Di Monte F, Wolpert C, Borggrefe M, Schimpf R, Sbragia P, et al. Short QT syndrome: Clinical findings and diagnostic therapeutic implications. Eur Heart J 2006; 27: 2440-2447.

35. Itoh $\mathrm{H}$, Horie $\mathrm{M}$, Ito $\mathrm{M}$, Imoto $\mathrm{K}$. Arrhthmogenesis in the short-QT syndrome associated with combined $H E R G$ channel gating defects: A simulation study. Circ J 2006; 70: 502-508.

36. Extramiana F, Antzelevitch C. Amplified transmural dispersion of repolarization as the basis for arrhythmogenesis in a canine ventricularwedge model of short-QT syndrome. Circulation 2004; 110: 3661 3666 .

37. Gaita F, Giustetto C, Bianchi F, Schimpf R, Haissaguerre M, Calo L, et al. Short QT syndrome: Pharmacological treatment. J Am Coll Cardiol 2004; 43: 1494-1499.

38. Wolpert C, Schimpf R, Giustetto C, Antzelevitch C, Cordeiro J, Dumaine R, et al. Further insights into the effect of quinidine in short QT syndrome caused by a mutation in HERG. J Cardiovasc Electrophysiol 2005; 16: 54-58.

39. Antzelevitch C, Pollevick GD, Cordeiro JM, Casis O, Sanguinetti MC, Aizawa Y, et al. Loss-of-function mutations in the cardiac calcium channel underlie a new clinical entity characterized by ST-segment elevation, short QT intervals, and sudden cardiac death. Circulation 2007; 115: $442-449$. 